\title{
A Frame-Based Analysis of Verbal Particles in Hungarian
}

\author{
Kata Balogh and Rainer Osswald
}

\begin{abstract}
The verbal particle in Hungarian raises a number of intriguing issues for any theory of the syntax-semantics interface. In this article, we aim at a formal account of the semantic contribution of various verbal particles in Hungarian and we show how the semantic representation of the clause can be compositionally derived. We will concentrate on the four frequent particles meg-, le-, el- and $f e l$-. Our approach makes use of a formalized version of Role and Reference Grammar and the framework of decompositional frame semantics. In particular, we give a formal representation of the boundary-setting function of the verbal particle in terms of decompositional frames which builds on a scalar change analysis. We furthermore analyze the interaction of the particle with resultative adjectives and provide a formal model of how their syntactic representations drive their frame-semantic composition.
\end{abstract}

Keywords Verbal particles $\cdot$ Hungarian $\cdot$ Scalar change $\cdot$ Decompositional frame semantics • Role and Reference Grammar.

\section{The Verbal Particle in Hungarian}

The verbal particle in Hungarian raises a number of intriguing issues for any theory of the syntax-semantics interface. In its default position immediately preceding the verb (1a), the verbal particle stands in complementary distribution with other verbal modifiers such as resultative predicates (1b), bare nouns and infinitival com-

\footnotetext{
1'Abbreviations: ACC 'accusative', ILL 'illative', INESS ‘inessive', PAST 'past tense', PL 'plural', POSS 'possessive', SUPESS 'superessive', SUBL 'sublative', VPTCL 'verbal particle'.
}

K. Balogh $(\varangle) \cdot$ R. Osswald

Institute of Linguistics and Information Science, Heinrich-Heine-Universität, 40204

Düsseldorf, Germany

e-mail: Katalin.Balogh@hhu.de 
plements. ${ }^{1}$ (Moreover, the immediate preverbal position can host the narrow focus constituent and sentential negation.)
a. Anna le-festette
a kerítés-t.
Anna VPTCL-paint.PAST the fence-ACC
'Anna painted the fence.'
b. Anna zöld-re festette a kerítés-t.
Anna green-SUBL paint.PAST the fence-ACC
'Anna painted the fence green.'

Hungarian verbal particles vary considerably with respect to their origin (e.g. Forgács 2004) and their semantic contribution (e.g. Kiefer and Ladányi 2000). ${ }^{2}$ Several particles express directionality (e.g. le- 'down', $k i$ - 'out') while others, including the frequent particle $m e g$-, are more difficult to classify on the basis of their lexical meaning. In the following, we will focus on interpretational aspects of the four verbal particles meg-, le- ('down, off'), el- ('away') and fel- ('up'), which, together with $k i$ - ('out') and be- ('in'), constitute the six oldest verbal particles in Hungarian (cf. Szoltész 1959). The overall goal of this article is to give a formal account of the semantic contribution of these particles, and to show how the semantic representation of the clause can be compositionally derived.

In a particle-verb combination, the verbal particle may contribute its original lexical meaning, as, for instance, directionality in the examples in (2), or the particle may have a more abstract semantic effect on the meaning of the verb as in (1a) above.
a. Anna le-szaladt a pincé-be.
Anna VPTCL-run.PAST the basement-ILL
'Anna ran down to the basement.'
b. Anna hirtelen el-szaladt.
Anna suddenly VPTCL-run.PAST
'Anna suddenly ran away.'

The directional meaning is mostly present in combination with verbs of motion as shown in (2). In this case, the verbal particle is often characterized as terminative (Kiefer and Ladányi 2000, pp. 25f; É. Kiss 2008). The example in (1a) illustrates the non-directional meaning contribution of the particle when combined with a nonmotion verb such as fest ('paint'). In such cases, Kiefer and Ladányi (2000) analyze the verbal particle as a "functor" that changes the Aktionsart of the predicate, e.g., by expressing a boundary condition. The introduction of an end or result condition is a frequent example of Aktionsart formation.

Traditionally, meg- has mostly been regarded as a pure aspectualizer or perfectivizer signaling perfective aspect and, thereby, determining the viewpoint aspect, as illustrated by the contrast between ( $3 a$ ) and (4a). In more recent studies, meg- is often taken as a delimiter (e.g., Bene 2009), signaling telicity (e.g., Kardos 2016)

\footnotetext{
${ }^{2}$ For more information on the historical development of the verbal particles in Hungarian see e.g. Szoltész (1959) and Pátrovics (2002).
} 
and, thus, relating to the Aktionsart (lexical aspect) of the predicate (e.g., Kiefer 2009; Kiefer and Németh 2012). The particle meg- is exclusively used in this way (4a), and the other particles discussed in this article can all be used in this way as shown, for example, in (4b) and (4c).

a. Száradt a törölköző.

[atelic, progressive]

dry.PAST the towel

'The towel was drying.'

b. Anna festette a kerítés-t.

Anna paint.PAST the fence-ACC

'Anna was painting the fence.'

c. Péter mosta a padló-t.

Peter wash.PAST the floor-ACC

'Peter was washing/mopping the floor.'

(4) a. Meg-száradt a törölköző.

VPTCL-dry.PAST the towel

'The towel (has) dried.'

b. Anna le-festette a kerítés-t.

Anna VPTCL-paint.PAST the fence-ACC

'Anna (has) painted the fence.'

c. Péter fel-mosta a padló-t.

Peter VPTCL-wash.PAST the floor-ACC

'Peter (has) washed/mopped the floor.'

The choice of the particle seems to be sensitive to the fine-grained semantic class of the base verb, at least to a certain extent. For instance, similar to the case of le-fest ('paint sth'), the particle le-combines with a number of other verbs which express a surface oriented incremental change such as le-töröl ('wipe down'), lesöpör ('sweep') and le-arat ('harvest'). Moreover, particle verbs of this group can co-occur with a resultative phrase, in which case the verbal particle occupies the preverbal position and the resultative phrase appears postverbally (5).

(5) Anna le-festette zöld-re a kerítés-t.

Anna VPTCL-painted green-SUBL the fence-ACC

'Anna painted the fence green.'

Other classes of verbs, including verbs of creation (e.g. meg-ír 'write',fel-épit 'build up'), allow for either a particle or a resultative phrase in the preverbal position, but reject the co-occurrence of the two. Yet others, including verbs of performance and perception of performances (e.g. el-énekel 'sing', meg-hallgat 'listen to'), seem not to allow for a resultative phrase at all.

Irrespective of the fact that the verbal particle affects the Aktionsart (lexical aspect) of the predicate, the syntactic position of the particle can have an influence on the aspectual interpretation (viewpoint aspect) of the utterance. The immediate preverbal 
position of the particle is associated with a perfective interpretation. The inverse order, by contrast, gives rise to a progressive interpretation (6). ${ }^{3}$

(6) Anna (éppen) festette le a kerítést, amikor meg-érkezett Péter. Anna (just) painted VPTCL the fence-ACC when VPTCL-arrived Peter 'Anna was painting the fence, when Peter arrived.'

In (6), the presence of the particle still indicates an intended result state while the postverbal position of the particle signals that the viewpoint aspect is progressive.

As mentioned above, the locative or directional meaning component of the particle, if available, is largely restricted to base verbs that denote movements or spatial positions. In these cases, Kiefer and Ladányi (2000) analyze the verbal particle as a predicate of location or direction and É. Kiss (2008) argues that the verbal particle has a terminative role and signals the end position of the moving theme as in (2a). The latter analysis seems problematic in view of examples like (2b), where the particle does not signal a final location or terminativity but the (deictic) direction of the movement.

Another possible function of verbal particles is to signal the inception or inchoation, i.e. the beginning of an event (or state). The particles meg-, el- ('away') and fel('up') can contribute this meaning component. Examples are el-alszik ('fall asleep'), meg-szeret ('get to love') and fel-zúg ('begin to buzz'). In (7), the base verb zúg ('buzz') denotes the production of a humming sound. The verbal particle $\mathrm{fel}$ - in (7b) signals the beginning of this activity or process.

a. Zúg a motor.

buzz the engine

'The engine is buzzing.'

b. Fel-zúg a motor.

VPTCL-buzz the engine

'The engine starts to buzz.'

Similarly, the particle verbs el-alszik ('fall asleep') and meg-szeret ('get to love') refer to the inchoation of an activity/state of sleeping and a state of loving. However, these predicates slightly differ from the one in (7b). As Kiefer and Ladányi (2000) point out, both el-alszik and meg-szeret can be modified by the adverbial lassan ('slowly'), cf. (8a) as opposed to fel-zúg (8b).

a. Anna lassan el-aludt.

Anna slowly VPTCL-slept

'Anna slowly fell a sleep.'

b. \#Lassan fel-zúg a motor.

slowly VPTCL-hum the engine

\footnotetext{
${ }^{3}$ The inverse order can also be triggered by other means: Narrow focus and negation are required to appear in the immediate preverbal position, causing the verbal particle to appear postverbally. In these cases, the viewpoint aspect of the clause remains neutralized or ambiguous.
} 
This suggests that some preparatory phase is present in the case of el-alszik and meg-szeret. We propose an analysis for both (7b) and (8a) representing inchoation as referring to the initial part of the activity/state contributed by the base verb. The difference in the possibility of adverbial modification of el-alszik and fel-zúg can be explained by differences in the temporal extension of this initial part.

\section{Scalar Analysis and Frame-Semantic Representation}

In Sect. 3 below, we propose a formal semantic analysis of the data discussed so far that combines a scalar analysis of the verbal particle with frame-based semantic representations of the lexical items involved. The purpose of the present section is twofold: First, we briefly review the scalar approach, which has been put forward as a general framework for the analysis of aspectual properties in the verbal domain by Filip (2008), Rappaport Hovav (2008), Kennedy and Levin (2008), and Beavers (2008), among others, based on the work of Krifka (1998) and Hay et al. (1999). Second, we introduce decompositional frame semantics as a representational means that integrates frame semantics with lexical decomposition and formal semantics. In particular, we will show how changes along a scale can be represented in frames.

The basic idea of the scalar approach is that gradual changes expressed by verbs or verbal constructions can be uniformly characterized as monotonic changes along an ordered set of degrees with respect to a certain dimension of measurement. Under this analysis, telicity comes about by boundaries on the scale, which can be inherent to the scale or imposed on it by the context. An early focus of the scalar approach was the analysis of deadjectival degree achievements such as widen and dry. The two verbs differ in that the scale associated with widen is open while the one associated with dry is closed, which has consequences for their default aspectual interpretation (Kearns 2007).

The scalar viewpoint has been fruitfully applied to the analysis (Kagan 2013, 2016; Zinova 2017). A common assumption of these approaches is that the prefixes determine a dimension of measurement on the basis of a scalar structure given by the base verb and, possibly, its direct, oblique, or prepositional object.

First applications of the scalar approach to the analysis of verbal particles and telicity in Hungarian are given in Kardos (2012, 2016) and Csirmaz (2012). As indicated in the previous section, the distinction between atelic and telic uses of deadjectival degree achievement verbs in Hungarian is marked by the presence of a verbal particle or another boundary-setting element in preverbal position. The contrast between (3a) and (4a) illustrates this for the intransitive verb szárad ('dry'), which is related to the adjective száraz ('dry'). The simple past tense use without a verbal particle shown in (3a) describes the process of drying, i.e., of getting drier. If the particle $m e g$ - is added, the resulting verb is telic and describes the accomplishment of getting dry; cf. (4a). This pattern carries over to transitive verbs such as fest ('paint') and mos ('wash'), which can be used to denote activities as well as accomplishments. When combined with a direct object that encodes a quantized predicate (cf. Krifka 
1998), the presence or absence of a verbal particle (or a resultative expression) determines the interpretation as an activity (atelic) or an accomplishment (telic), respectively. This contrast is illustrated in (3b) versus (4b) and in (3c) versus (4c). ${ }^{4}$ According to the descriptive analysis of Kardos (2016), the verbal particle (or a resultative expression) encodes an event-maximalization operator in the sense of Filip (2008) which goes along with the presence of a closed scale. That is, the particle in preverbal position imposes a bound on the event denoted by the verb. In the formal representations presented below, this corresponds to the existence of a final event stage in which the maximal value of the associated scalar attribute holds at the relevant event participant. For instance, in the final stage of a drying event described as telic, the affected object is characterized as having maximal dryness (or zero moisture).

The formal semantic framework employed in the following makes use of decompositional frames (Kallmeyer and Osswald 2013; Osswald and Van Valin 2014). A crucial assumption of frame semantics is that attributes (features, functional relations) play a central role in the organization of semantic and conceptual knowledge and semantic representation (Barsalou 1992; Löbner 2014). Frames are thus inherently structured representations whose semantic components (participants, subevents etc.) can be recursively accessed via attributes. Another aspect of the presented approach is that semantic computation can be understood as the incremental construction of (minimal) frame models based on the input, the context, the lexicon, and background knowledge, while composition is basically realized by frame unification under constraints.

A standard decomposition structure like the one shown in (9) for transitive break (cf., e.g., Levin and Rappaport Hovav 2011) can be represented as an event frame of type causation which has a CAUSE component of type activity and an EFFECT component of type change-of-state, which in turn has a RESULT component of type broken.

\section{(9) $\quad[[x$ ACT $]$ CAUSE $[$ BECOME $[y$ BROKEN $]]]$}

Moreover, the participants $x$ and $y$ are represented as the EFFECTOR of the activity and the PATIENT of the result component, respectively. The overall frame structure is graphically depicted in Fig. 1a.

Formally, we define frame structures as base-labeled feature structures with types and relations as introduced in Kallmeyer and Osswald (2013). Structures of this type arise as canonical models of certain attribute-value descriptions. For example, the frame structure in Fig. 1a is the canonical model of the (closed) attribute-value description in (10). ${ }^{5}$ The attribute-value matrix shown in Fig. $1 \mathrm{~b}$ can be seen as a notational variant of this description.

\footnotetext{
${ }^{4}$ As noted by Kardos (2016, pp. 4ff, 28ff), verbs of consumption and creation behave somewhat differently in that they may receive a telic interpretation even without a verbal particle if the direct object has quantized reference.

${ }^{5}$ The corresponding open (or unlabelled) description, which lacks the leading label $e$, can be seen as a one-place predicate that is either true or false at the nodes of a frame structure.
} 
a)

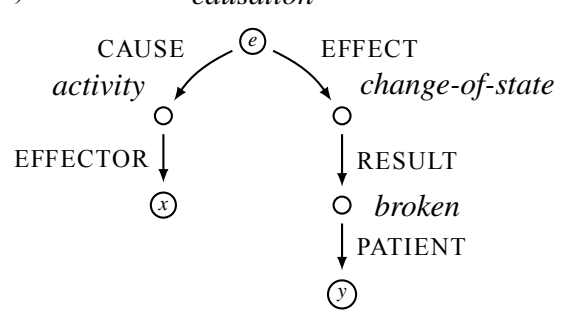

b)

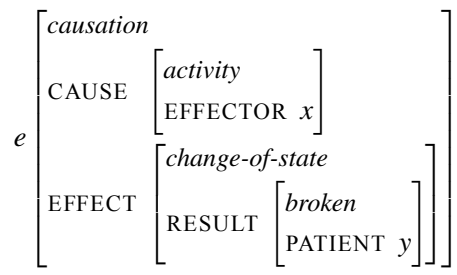

Fig. 1 Frame representation and attribute-value matrix

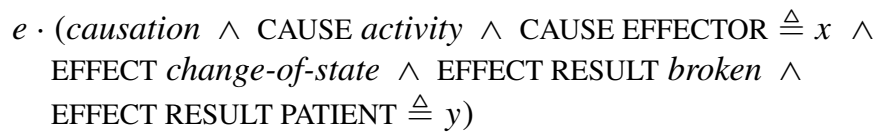

Attribute-value descriptions have a straightforward translation into expressions of first-order predicate logic. The respective translation of (10) is given in (11), with $e$, $x$ and $y$ used as free variables (or constants) and with the additional requirement that all attribute relations (written in small caps) are functional.

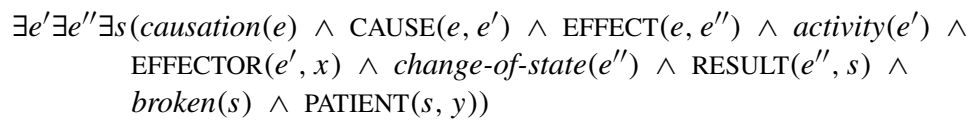

The structure in Fig. 1a can then be characterized as the minimal model of (11) in the usual sense of first-order predicate logic, under the assumption that attribute relations are functional.

The formal framework just sketched has no direct means to encode universal quantification. In order to be able to represent the implicit quantification over subevents (or subintervals) involved in the characterization of a scalar change, we therefore extend the framework by allowing frame types as values of attributes. To this end, we introduce nominals (names, constants) for frame types into the description language, which means to treat frame types as "first class citizens" of the frame models. More formally, we assume that every (open) attribute-value description can give rise to the name of a frame type, which is notationally indicated by enclosing the description in double lines. For example, \|causation $\|$ and $\|$ broken $\wedge$ PATIENT : phys-obj\| are names of frame types. Frame types are related to their instances and to each other by the relations is-instance-of (inst) and is-subtype-of (subtype), respectively. For instance, \|causation $\|$ is-subtype-of $\|$ event $\|$ is assumed to be true.

In order to characterize an event with respect to its progression of incremental, ongoing changes, the event is assumed to have an attribute PROG(RESSION) whose value specifies the type of the change in question. Processes of drying can then be characterized as having an attribute PROG whose value is the type \|becoming-drier\|. More precisely, the type in question is $\|$ becoming-drier $\wedge$ ENTITY $x \|$, where $x$ is the entity that is drying. This frame type is to be seen as a shorthand for the more complex 


$$
\left.\| \begin{array}{l}
\| \begin{array}{l}
\text { incremental-change } \\
\text { ENTITY } x
\end{array} \\
\text { INIT }\left[\begin{array}{ll}
\text { stage } \\
\text { ENTITY } & x \\
\text { MOISTURE } & 1
\end{array}\right] \\
\text { FIN }\left[\begin{array}{l}
\text { stage } \\
\text { ENTITY r } \\
\text { MOISTURE }
\end{array}\right]
\end{array}\right] \|
$$

Fig. 2 Frame-semantic representation of a complex type of incremental-change

type shown in Fig. 2, which provides an explicit decomposition of the underlying change of state: Events of the type in question are events of type incremental-change of an ENTITY $x$ such that the MOISTURE value at the FIN(AL) stage (of $x$ ) is lower than MOISTURE value at the INI(TIAL) stage.

Characterizing an event $e$ by $\mathrm{PROG} \triangleq T$ is meant to express the fact that every (appropriate) event segment $e^{\prime}$ of $e\left(e^{\prime}\right.$ segm $\left.e\right)$ is an instance of the type $T\left(e^{\prime}\right.$ inst $\left.T\right)$. That is, the following constraint schema is required to be valid:

$$
e \cdot \mathrm{PROG} \triangleq T \wedge e^{\prime} \operatorname{segm} e \rightarrow e^{\prime} \text { inst } T
$$

It is this schema that makes explicit the universal quantification over subevents encoded by PROG. Note that (12) applies only to event segments which are referentially introduced. That is, the schema is applied "on demand".

\section{Semantic Analysis of Verbal Particles}

A central pattern of our analysis is that verbal particles in Hungarian, and other lative-marked verbal modifiers, can turn activity (or process) descriptions into accomplishments by adding a boundary condition to the event frame associated with the verb. ${ }^{6}$ Following the outline sketched in Sect. 2 , the boundary information is imposed by syntax-driven frame composition on a scale or dimension of change component within the event.

The frame representation of the drying process and the effect of adding megis sketched in Fig. 3. The process is modeled as a progression characterized by an

\footnotetext{
${ }^{6}$ Turning atelic events into telic ones is a rather frequent function of the verbal particle in Hungarian. Note, however, that this function is not always present. As É. Kiss (2008) and Kiefer and Németh (2012) point out, there are particle verbs denoting a static (and hence inherently atelic) event; moreover, duplication of the verbal particle signals iteration (as non habitual repetition), which is atelic as well. In the former group, the base verb is either a perception verb or a verb expressing spatial position. In these cases, the verbal particle contributes directionality.
} 

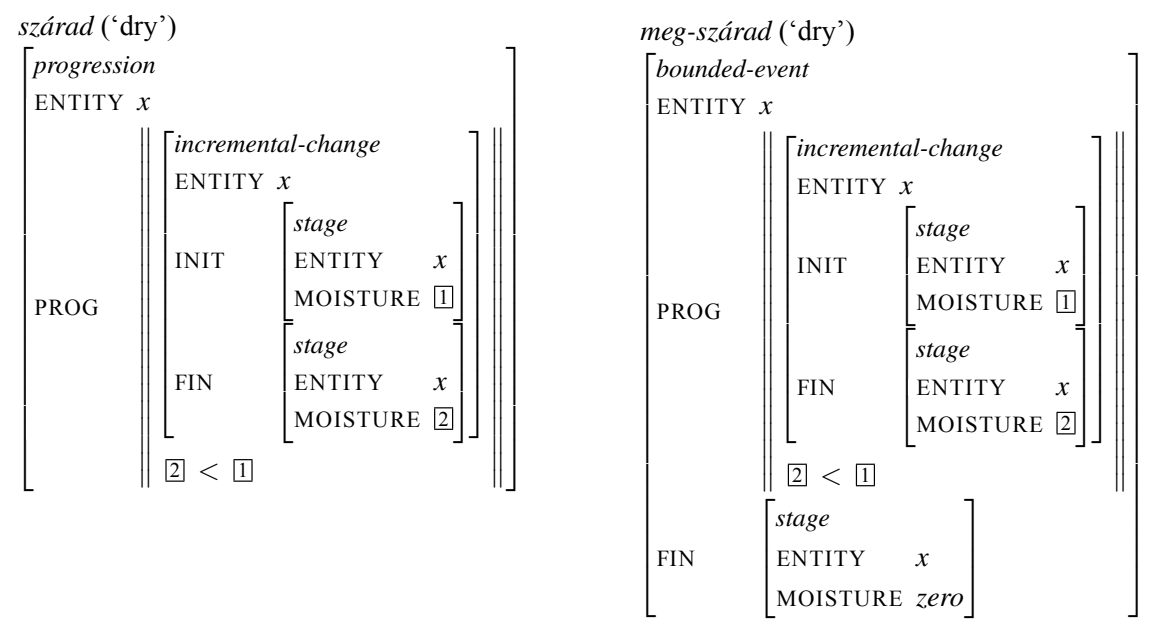

Fig. 3 Frame-semantic representation of combining meg-with szárad ('dry')

incremental decrease of moisture. The value of PROG is the frame type which characterizes the subevents of the progression. The particle meg-adds a FINAL attribute to the progression frame, and the constraint shown in (13) picks out the type of the FINAL value from the progression structure. ${ }^{7}$

$$
\text { FINAL: stage } \wedge \text { PROG } \| \text { FINAL } \| \triangleq T \Rightarrow \text { FINAL is-of-type } T
$$

A further constraint enforces the extremal value of the scalar attribute in the final stage.

The above proposal can be directly applied to the analysis of verbs expressing an incremental change. Compare again the sentence without verbal particle in (3b), repeated as (14a), with the sentence in (4b) with the particle le- ('down, off') in its default preverbal position, repeated as (14b).

a. Anna festette a kerítés-t.

[atelic]

Anna painted the fence-ACC

'Anna was painting the fence.'

b. Anna le-festette a kerítés-t.

[telic]

Anna VPTCL-painted the fence-ACC

'Anna painted the fence.'

The base verb fest ('paint') denotes an event of type active-progression which goes along with an incremental change of the theme. More precisely, as indicated by the frame representation shown in Fig. 4, the base verb fest expresses an action by the ACTOR $x$, affecting the THEME $y$ by incrementally putting more and more paint on

${ }^{7} \phi \Rightarrow \psi$ is short for $\forall x(\phi(x) \rightarrow \psi(x))$, where $\phi$ and $\psi$ are one-place predicates. 


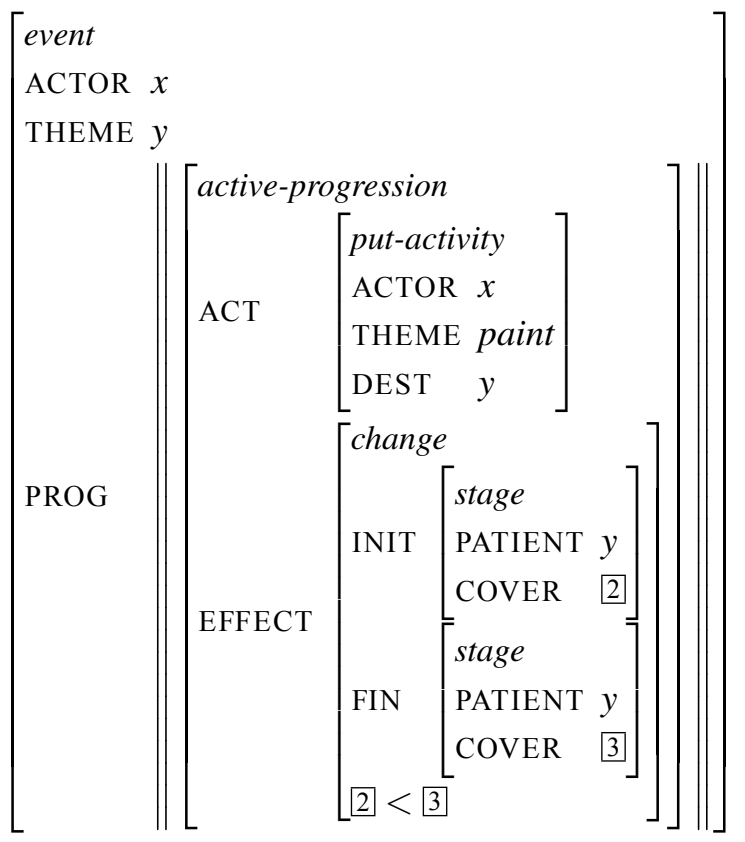

Fig. 4 Frame representation of fest 'paint'

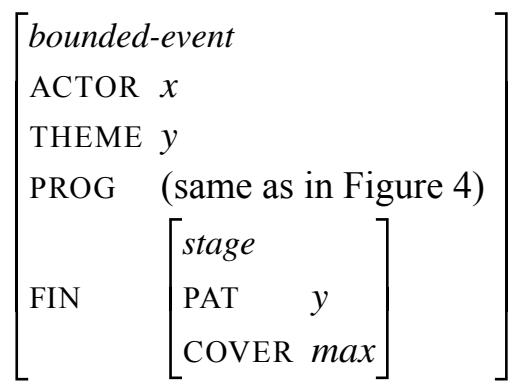

Fig. 5 Frame representation of le-fest 'paint' (bounded)

the surface of $y$. In this incremental change of the surface, for each arbitrary part of the progression it holds that at the final stage of that part the surface is covered more than it was at the initial stage of that given part. In (14b), by comparison, the verbal particle le- ('down') contributes the final stage, turning the event into a bounded event (Fig. 5). 


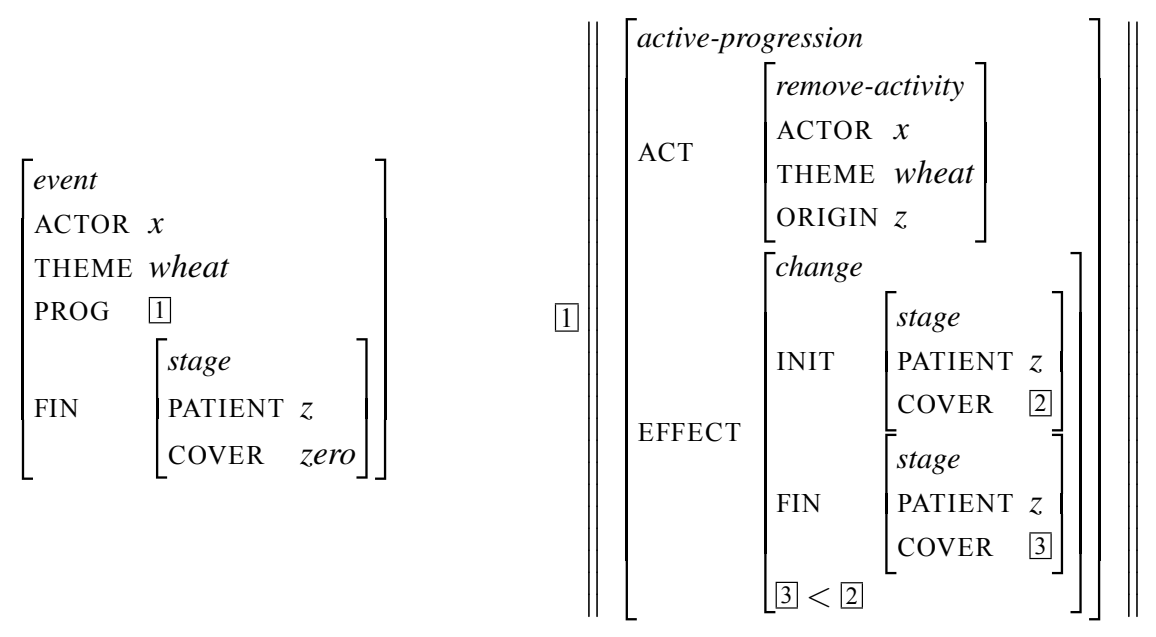

Fig. 6 Frame representation of le-arat 'reap/harvest'

Consider now example (15) with the particle verb le-arat ('reap/harvest').
A gazda le-aratta
a búzá-t.

the farmer VPTCL-reaped the wheat-ACC

'The farmer reaped the wheat.'

The base verb expresses an activity of removing the THEME (wheat) from an unspecified location $z$ such that its coverage will incrementally decrease. This is represented in the frame type shown on the right of Fig. 6: the value of the ACT attribute is the remove-activity with the ORIGIN $z$, which is identical to the PATIENT of the initial and final stages of the change. Similarly to the previous examples, the verbal particle signals the final stage at which the coverage of $z$ is zero (or minimal). Note that in the above example, the THEME of the main event is not identical to the PATIENT of the incremental change. Although less frequent, there are examples of reap/harvest where the changing object is expressed as the direct object of the utterance:

$$
\begin{aligned}
& \text { Le-arat-ták Devecser határ-á-ban péntek-en az első [...] } \\
& \text { VPTCL-reap-3PL Devecser border-3POSS-INESS Friday-SUPESS the first } \\
& \text { kísérleti energiaültetvény-t } \quad[\ldots] \\
& \text { experimental energy.plantation-ACC } \\
& \text { 'At the border of Devecser, the first energy plantation was reaped on Friday } \\
& {[\ldots]}
\end{aligned}
$$

(Magyar Nemzet Online, 30 November 2012)

The examples of the inchoative function of the particles meg-, el- and $\mathrm{fel}$ - mentioned in Sect. 1 are partially in line with the observations made about the inchoative use of the Russian prefix $z a$ - as presented by Zinova (2017). The inchoative func- 


$$
e\left[\begin{array}{l}
\text { inchoation } \\
\text { POST } e^{\prime}\left[\begin{array}{ll}
\text { process } & \\
\text { ENITITY } & x \\
\text { MANNER } & b u z z
\end{array}\right]
\end{array}\right]
$$

Fig. 7 Frame representation of fel-zúg 'begin to buzz'

tion of the verbal particle is compatible with base verbs expressing a state, activity or process. We represent this use as expressing an event of type inchoation with a POST(ERIOR) attribute whose value is the posterior event of the inchoation, i.e., a state/activity/process of the type denoted by the base verb; cf. Fig. 7.

\section{Semantic Composition and the Syntax-Semantics Interface}

As to the modeling of the interaction between syntax and semantics we apply the framework of Role and Reference Grammar (RRG; Van Valin and LaPolla 1997; Van Valin 2005). RRG is a surface oriented grammar, developed from a typological perspective and explicitly concerned with the interplay of syntax, semantics and pragmatics. The layered structure of the clause in RRG aims to capture universal characteristics of clause structure in natural languages, while language specific features are expressed via a range of constraints. The layered structure reflects the distinction between predicates, arguments, and non-arguments. The core layer consists of the nucleus, which specifies the (verbal) predicate, and the syntactic arguments. The clause layer contains the core as well as extracted arguments. Each of the layers can have a periphery where adjuncts are attached to; cf. Fig. 8 (where 'RP' stands for referential phrase).

The heart of the grammatical system of RRG is a bi-directional linking algorithm between the syntactic and the semantic representations of the sentence, reflecting both processes of production and comprehension. The interaction of syntax and semantics is furthermore influenced by discourse-pragmatics (the focus structure of the utterance) and language-specific constructional schemas. In our analysis we rely on a formalized version of RRG, following Osswald and Kallmeyer (2018), in which tree nodes can carry features. This allows for the elimination of the PRED node, which has no other function than marking the element as predicative, and which can be simply represented by the feature [PRED +]. Features can also be used to establish the link between syntactic elements and the corresponding semantic representations.

We propose different structural representations for the verbal particle and the resultative predicate. The main difference is that the latter construction is analyzed as a nuclear cosubordination (cf. Van Valin 2005), which corresponds to complex 
predicate formation, while the particle is taken as a modifier of the verbal nucleus; cf. Fig. 9. By this distinction we argue against a uniform account of the semantic contribution associated with the preverbal position as proposed by É. Kiss (2008), who claims that the verbal particle in this position functions as a resultative, terminative or locative secondary predicate of the theme argument. This proposal seems to be too restrictive since verbal particles do not necessarily introduce a secondary predicate. Consider, for instance, the particle-verb combination in (17), for which the assumption of a secondary predication is hard to justify.

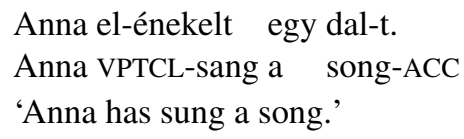

Anna el-énekelt egy dal-t.

Anna VPTCL-sang a song-ACC

'Anna has sung a song.'

Based on similar observations, Bene (2009) argues that the verbal particle merely functions as a delimiter rather than as a secondary predicate. In our analysis, we aim to make this distinction explicit by analyzing the construction of a resultative adjectiveverb combination as a nuclear cosubordination with two predicative elements and the particle as a modifier of the verbal nucleus.

In the formalized version of RRG introduced in Osswald and Kallmeyer (2018), the syntactic inventory, whose elements are subject to compositional syntactic operations such as substitution and adjunction, consists of elementary trees in the sense of Lexicalized Tree Adjoining Grammars (Joshi and Schabes 1997). The elemen-

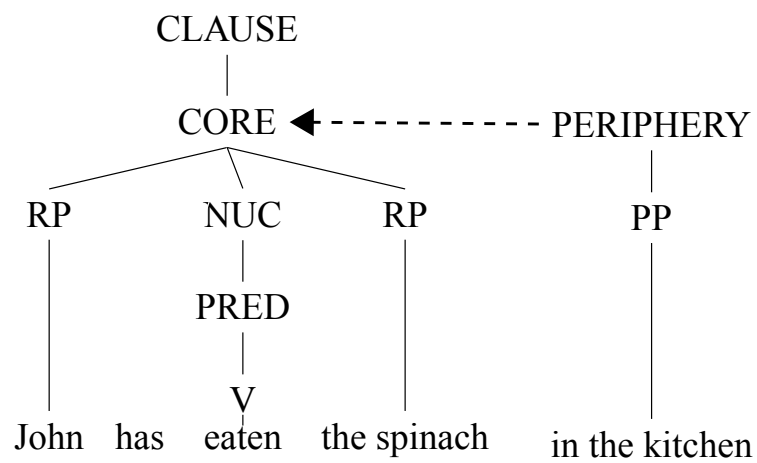

Fig. 8 Universal elements in the RRG clause structure
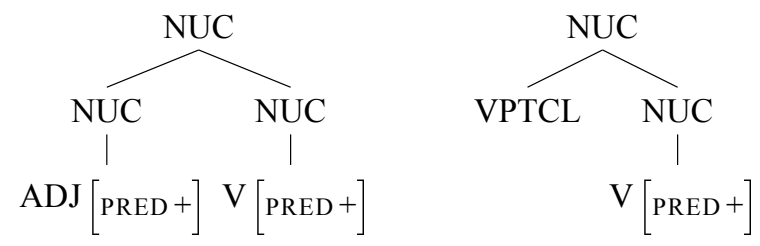

Fig. 9 Structures for resultative predicates and verbal particles 
tary trees encode full argument projections. They are specified in a modular way in the so-called metagrammar (Crabbé et al. 2013). The metagrammar is basically a declarative system of tree descriptions about node dominance and precedence which allows one to define classes of grammatically relevant tree constraints. These classes can then be combined to generate the elementary trees as minimal models of the constraints. It is thus the level of the metagrammar where important grammatical generalizations about the elementary constructions of a language are expressed.

The metagrammar classes used in the analysis of our examples are sketched in (18). ${ }^{8}$

a.

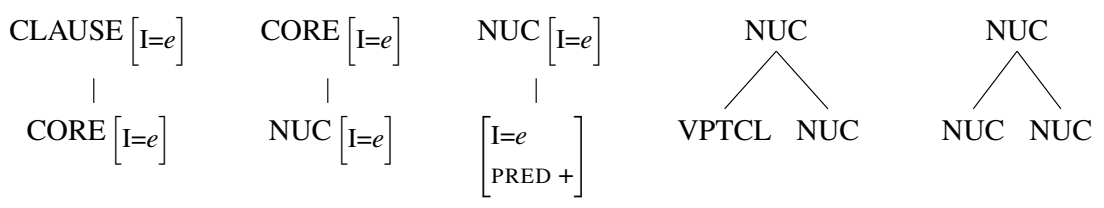

b.

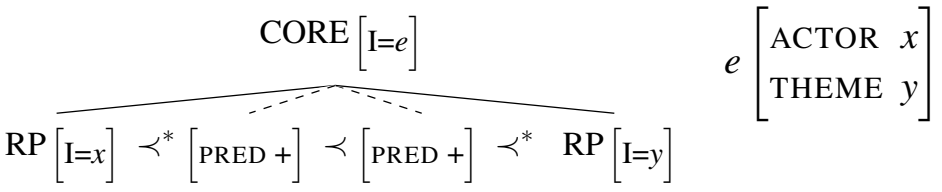

c. $\quad \mathrm{NUC}[\mathrm{I}=e]$

VPTCL $\mathrm{V}\left[\begin{array}{l}\mathrm{I}=e^{\prime} \\ \mathrm{PRED}+\end{array}\right]$

$e\left[\begin{array}{l}\text { bounded-event } \\ \text { FINAL } T\end{array}\right] \quad e^{\prime}\left[\begin{array}{l}\text { event } \\ \text { PROG }\end{array}\right]$

d. $\quad \mathrm{NUC}[\mathrm{I}=e]$

$\operatorname{ADJ}\left[\begin{array}{l}\mathrm{I}=s \\ \text { PRED }+\end{array}\right] \mathrm{V}\left[\begin{array}{l}\mathrm{I}=e^{\prime} \\ \mathrm{PRED}+\end{array}\right]$

$e\left[\begin{array}{l}\text { bounded-event } \\ \text { FINAL } s[\text { stage }]\end{array}\right] \quad e^{\prime}\left[\begin{array}{l}\text { event } \\ \text { PROG } \top\end{array}\right]$

The tree fragment in (18b), together with its semantic contribution, describes a structure with the actor argument in the preverbal field and the theme argument in the postverbal field. The tree fragment in (18c) and its associated semantic contribution describes the verbal particle in its default position and its semantic contribution as adding a boundedness condition to the event. The fragment in (18d) describes a resultative adjective in the preverbal position contributing a final stage $s$ (boundedness condition) in which a secondary predicate holds.

\footnotetext{
${ }^{8}$ In the illustrations, $\prec *$ stands for precedence, $\prec$ for immediate precedence, edges by solid lines stand for immediate dominance, and the dashed lines for dominance.
} 


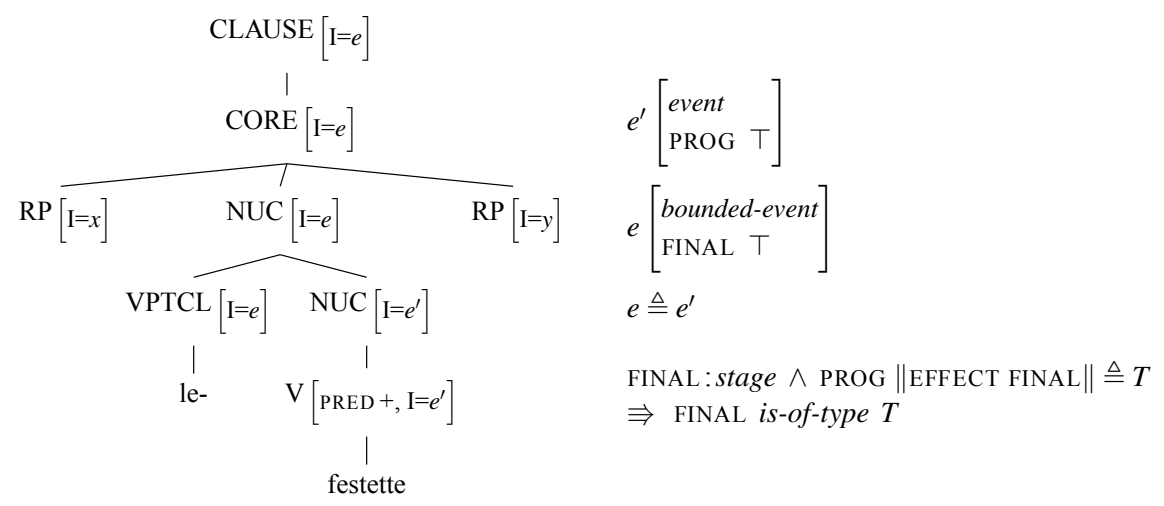

Fig. 10 Interaction between syntax and semantics for sentence (14b)

Let us apply the proposed analysis to the example in (14c). Figure 10 illustrates the interaction between syntax (in terms of RRG) and frame semantics for particleverb combinations like le-festette ('VPTCL-painted'). The verb festette contributes an event $e^{\prime}$ with a progression component while the verbal particle contributes a bounded event $e$ with a final stage. The equation $e \triangleq e^{\prime}$ states that these two components both contribute to the same event rather than expressing two separate events. The constraint shown at the lower right of Fig. 10 corresponds to the constraint in (13) and ensures that the final stage of the bounded event and the final stage of the effect of the incremental progression must be of the same type. At the end of the derivation, the semantic composition leads to the representation illustrated in Fig. 5.

As shown in example (1b), repeated as (19), resultative predicates also function as verbal modifiers, occupying the immediate preverbal position.

(19) Anna zöld-re festette a kerítés-t.

Anna green-SUBL painted the fence-ACC

'Anna painted the fence green.'

The combination of the preverbal resultative predicate and the verb is analyzed as a nuclear cosubordination with both NUC elements being predicative. The resultative predicate zöld-re ('green-SUBL') in its default position also indicates boundedness (telicity), and being predicative it provides a secondary predication of the theme: in the final stage of the changing theme its color is green. The constraint on the final stages is the same as before; cf. Fig. 11.

Verbal particles can also co-occur with resultative predicates, which poses further interesting questions for the syntax-semantics interface. If the particle and the resultative predicate co-occur in a neutral sentence, they cannot both be preverbal. In 
this case, the particle occupies the immediate preverbal position while the resultative phrase appears postverbally; see (20a) versus (20b). ${ }^{9}$
a. Anna le-festette zöld-re a kerítés-t.
Anna VPTCL-painted green-SUBL the fence-ACC
'Anna painted the fence green.'
b. *Anna zöld-re le-festette a kerítés-t.
Anna green-SUBL VPTCL-painted the fence-ACC

The analysis of (20a) is in line with the analysis of the previous sentences. The particle and the verb form a modified nucleus (le-festette) that forms a complex predicate with the resultative predicate (le-festette zöld-re) by nuclear cosubordination. The final derivations for the examples in (19) and (20a) lead to the same semantic representation, in accordance with our intuitions; cf. Figs. 11, 12, and 13. Note that the progression component, that is, the representation of the incremental change, is the same in all three cases. Examples (19) and (20a) differ from (14b) in that the latter does not contain a secondary predication but merely a delimiter indicating boundedness (telicity).

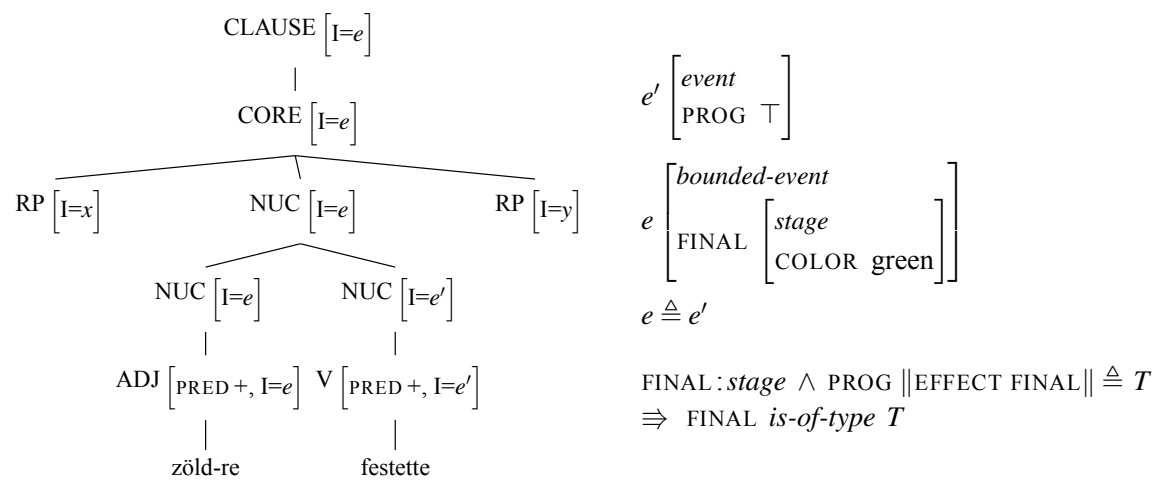

Fig. 11 Interaction between syntax and semantics for example (19)

\footnotetext{
${ }^{9}$ The linearization in (20b) is grammatical in case the resultative predicate gets a contrastive topic intonation. In this article, we only consider neutral sentences.
} 

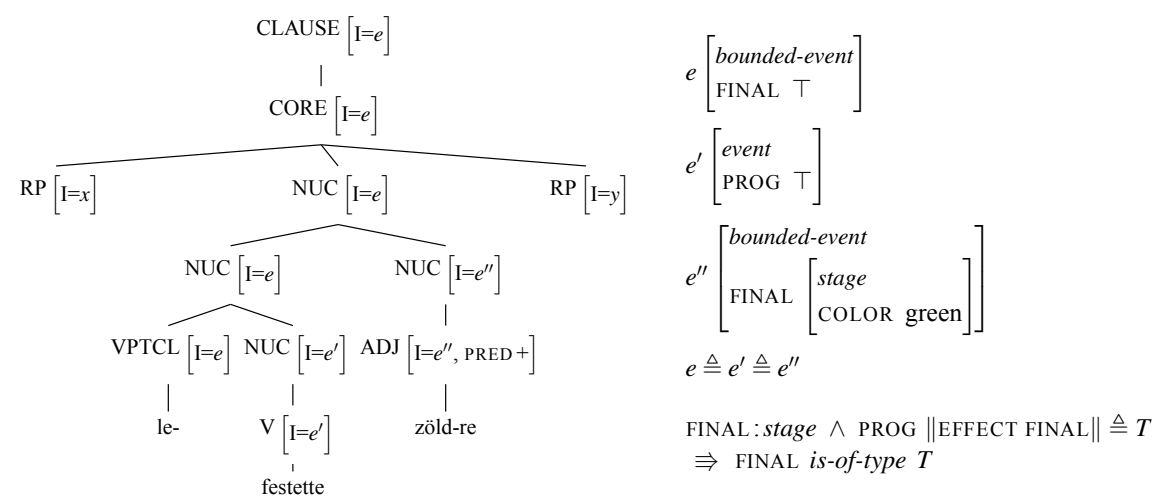

Fig. 12 Interaction between syntax and semantics for example (20a)

$$
\left[\begin{array}{ll}
\text { bounded-event } \\
\text { ACTOR } & x \\
\text { THEME } & y \\
\text { PROG } & \text { (same as in Figure 4) } \\
\text { FINAL } & {\left[\begin{array}{ll}
\text { stage } & \\
\text { PAT } & y \\
\text { COVER } & \text { max } \\
\text { COLOR } & \text { green }
\end{array}\right]}
\end{array}\right]
$$

Fig. 13 Derived semantics for (19) and (20a)

\section{Summary}

The main goal of this article was to propose a formal account of the semantic contribution of various verbal particles in Hungarian and to sketch how the semantic representation of the clause can be compositionally derived. We did not aim at a full-fledged descriptive characterization of all the possible particle-verb combinations in Hungarian but concentrated on frequent functions and their formal semantic characterization. While the previous analyses mentioned in Sect. 1 offer adequate insights to the various meaning contributions of the Hungarian verbal particles, they leave open the question of the precise semantic representation and the compositional mechanisms involved. Furthermore, we argued that the characterization of É. Kiss (2008) of the particle as a secondary predication is too strong. Kiefer and Ladányi (2000) and Kiefer (2009) provide a wide coverage descriptive analysis but lack a well-defined formal characterization. They introduce nine productive Aktionsart formations by verbal particles, but without specifying their semantic representation formally. We presented a formal, compositional analysis of some of their basic descriptive insights. We focussed on frequent cases of the telicizing function of verbal particles and sketched a representation of the inchoative meaning contribution. 
The use of the framework of decompositional frame semantics proved useful for this purpose as it provides a formal tool for a fine-grained representation of the event structure of the predicate and for the Aktionsart-effects of modified and complex predicates. The semantic characterization of verbal particles in our analysis is close to the analysis of Kardos (2016), among others. The main contribution of our approach is an explicit semantic and syntactic representation and a compositional model.

Acknowledgements The research presented in this article was supported by the Collaborative Research Centre 991 "The Structure of Representations in Language, Cognition, and Science" funded by the German Research Foundation (Deutsche Forschungsgemeinschaft). We would like to thank the anonymous reviewers for their valuable comments on earlier drafts of this article.

\section{References}

Barsalou, L. W. (1992). Frames, concepts, and conceptual fields. In A. Lehrer \& E. F. Kittay (Eds.), Frames, fields, and contrasts: New essays in semantic and lexical organization (pp. 21-74). Hillsdale: Lawrence Erlbaum.

Beavers, J. (2008). Scalar complexity and the structure of events. In J. Dölling, T. Heyde-Zybatow, \& M. Schäfer (Eds.), Event structures in Linguistic form and interpretation, language, context and cognition (pp. 245-265). Berlin: Mouton de Gruyter.

Bene, A. (2009). What is really the function of the verbal particle in Hungarian. Suvremena Lingvistika, 35(68), 207-220.

Crabbé, B., Duchier, D., Gardent, C., Le Roux, J., \& Parmentier, Y. (2013). XMG: eXtensible MetaGrammar. Computational Linguistics, 39(3), 591-629.

Csirmaz, A. (2012). Scales, verbs and verbal modifiers. University of Utah (unpublished manuscript).

É. Kiss, K. (2008). The function and the syntax of the verbal particle. In K. É. Kiss (Ed.), Event structure and the left periphery. Studies on Hungarian (pp. 17-55). Dordrecht: Springer.

Filip, H. (2008). Events and maximalization: The case of telicity and perfectivity. In S. Rothstein (Ed.), Theoretical and crosslinguistic approaches to the semantics of aspect (pp. 217-256). Amsterdam: John Benjamins.

Forgács, T. (2004). Grammaticalization and preverbs. Acta Linguistics Hungarica, 51(1-2), 45-84.

Hay, J., Kennedy, C., \& Levin, B. (1999). Scalar structure underlies telicity in "degree achievements". In T. Matthews \& D. Strolovitch (Eds.), Proceedings of SALT IX, Ithaca, NY (pp. $127-$ 144). CLC Publications.

Joshi, A. K., \& Schabes, Y. (1997). Tree-adjoining grammars. In G. Rozenberg \& A. Salomaa (Eds.), Handbook of formal languages. Vol. 3: Beyond words (pp. 69-123). Berlin: Springer.

Kagan, O. (2013). Scalarity in the domain of verbal prefixes. Natural Language and Linguistic Theory, 31, 483-516.

Kagan, O. (2016). Scalarity in the verbal domain: The case of verbal prefixation in Russian. Cambridge: Cambridge University Press.

Kallmeyer, L., \& Osswald, R. (2013). Syntax-driven semantic frame composition in lexicalized tree adjoining grammars. Journal of Language Modelling, 1(2), 267-330.

Kardos, É. (2012). Toward a scalar semantic analysis of telicity in Hungarian. Ph.D. thesis, Debreceni Egyetem.

Kardos, É. (2016). Telicity marking in Hungarian. Glossa, 1(1), 41:1-37.

Kearns, K. (2007). Telic senses of deadjectival verbs. Lingua, 117, 26-66. 
Kennedy, C., \& Levin, B. (2008). Measure of change: The adjectival core of degree achievements. In L. McNally \& C. Kennedy (Eds.), Adjectives and adverbs (pp. 156-182). Oxford: Oxford University Press.

Kiefer, F. (2009). Types of temporal adverbials and the fine structure of events. In K. É. Kiss (Ed.), Adverbs and adverbial adjuncts at the interfaces (pp. 247-269). Berlin/Boston: De Gruyter Mouton.

Kiefer, F., \& Ladányi, M. (2000). Az igekötők [The verbal particles]. In F. Kiefer (Ed.), Strukturlis magyar nyelvtan, Vol. 3: Morfológia (pp. 453-518). Budapest: Akadémiai Kiadó.

Kiefer, F., \& Németh, B. (2012). Amikor az igekötő nem telicizál [When the verbal particle does not telicize]. Nyelvtudományi Közlemények, 108, 267-273.

Krifka, M. (1998). The origins of telicity. In S. Rothstein (Ed.), Events and grammar (pp. 197-235). Dordrecht: Kluwer Academic Publishers.

Levin, B., \& Rappaport Hovav, M. (2011). Lexical conceptual structure. In C. Maienborn, K. von Heusinger, \& P. Portner (Eds.), Semantics. An international handbook of natural language meaning (Vol. 1, pp. 420-440). Berlin: Mouton de Gruyter.

Löbner, S. (2014). Evidence for frames from human language. In T. Gamerschlag, D. Gerland, R. Osswald, \& W. Petersen (Eds.), Frames and concept types (pp. 23-67). Dordrecht: Springer.

Osswald, R., \& Kallmeyer, L. (2018). Towards a formalization of Role and Reference Grammar. In R. Kailuweit, E. Staudinger, \& L. Künkel (Eds.), Applying and expanding Role and Reference Grammar (NIHIN Studies) (pp. 355-378). Freiburg: Albert-Ludwigs-Universität, Universitätsbibliothek.

Osswald, R., \& Van Valin, Jr., R. D. (2014). FrameNet, frame structure, and the syntax-semantics interface. In T. Gamerschlag, D. Gerland, R. Osswald, \& W. Petersen (Eds.), Frames and concept types (pp. 125-156). Dordrecht: Springer.

Pátrovics, P. (2002). Néhány gondolat a magyar igekötốk eredetéről, valamint aspektus- és akcimóminőség-jelölő funkciójuk (ki)alakulásáról. Magyar Nyelvốr, 126(4), 481-489.

Rappaport Hovav, M. (2008). Lexicalized meaning and the internal temporal structure of events. In S. Rothstein (Ed.), Theoretical and crosslinguistic approaches to the semantics of aspect (pp. 13-42). Amsterdam: John Benjamins.

Szoltész, K. (1959). Az ósi magyar igekötók [The ancient Hungarian verbal particles]. Budapest: Akademiai Kiadó.

Van Valin, R. (2005). Exploring the syntax-semantics interface. Cambridge: Cambridge University Press.

Van Valin, Jr., R. D., \& LaPolla, R. J. (1997). Syntax. Cambridge: Cambridge University Press.

Zinova, J. (2017). Russian verbal prefixation: A frame semantic analysis. Ph.D. thesis, HeinrichHeine-Universität Düsseldorf.

Open Access This chapter is licensed under the terms of the Creative Commons Attribution 4.0 International License (http://creativecommons.org/licenses/by/4.0/), which permits use, sharing, adaptation, distribution and reproduction in any medium or format, as long as you give appropriate credit to the original author(s) and the source, provide a link to the Creative Commons license and indicate if changes were made.

The images or other third party material in this chapter are included in the chapter's Creative Commons license, unless indicated otherwise in a credit line to the material. If material is not included in the chapter's Creative Commons license and your intended use is not permitted by statutory regulation or exceeds the permitted use, you will need to obtain permission directly from the copyright holder. 